\title{
Results from Multi Technique Investigation of Pottery from Different Early Neolithic Sites in Albania
}

\author{
Erinda Ndreçka $^{1,2}$, Nikolla Civici' ${ }^{1}$, Enkeleida Beqiraj ${ }^{3}$, Ilir Gjipali ${ }^{4}$ \\ ${ }^{1}$ Institute of Applied Nuclear Physics, University of Tirana, Tirana, Albania \\ ${ }^{2}$ Department of Physics, University of Tirana, Tirana, Albania \\ ${ }^{3}$ Department of Earth Sciences, Polytechnic University of Tirana, Tirana, Albania \\ ${ }^{4}$ Institute of Archaeology, Centre of Albanian Studies, Tirana, Albania \\ Email: erinda.ndrecka@hotmail.com
}

How to cite this paper: Ndreçka, E., Civici, N., Beqiraj, E. and Gjipali, I. (2017) Results from Multi Technique Investigation of Pottery from Different Early Neolithic Sites in Albania. Journal of Materials Science and Chemical Engineering, 5, 10-26.

https://doi.org/10.4236/msce.2017.59002

Received: July 25, 2017

Accepted: September 25, 2017

Published: September 28, 2017

Copyright $\odot 2017$ by authors and Scientific Research Publishing Inc. This work is licensed under the Creative Commons Attribution International License (CC BY 4.0).

http://creativecommons.org/licenses/by/4.0/

\begin{abstract}
The archaeological excavations of the Neolithic sites in Albania show that this area has been the center of the confluence of different cultures with various levels of development and social organization. This is reflected in the pottery manufacturing, which during early Neolithic is classified in three major groups. The pottery from the Early Neolithic site at Kolsh, situated in north east, shows similarities with all the other cultures of central Balkans, the shards from the site Blaz in the north-west region show an Adriatic-Mediterraean character, while the south culture represented by Vashtemi and Podgorie sites appears to show cultural report with early Neolithic in the area of Thessaloniki. During the last years, the Institute of Applied Nuclear Physics of the University of Tirana and the Institute of Archaeology of the Center of Albanian Studies have initiated a cooperative study of the ceramic finds which aims at a better characterization and classification of the ceramic finds. In this context Optical Microscopy (OM), EDXRF, micro-XRF and XRD were used for the elemental and structural characterization of ceramic samples. Some data on the fabric texture, inclusions, decoration materials and elemental composition of the shards from pottery samples belonging to the mentioned Early Neolithic sites in Albania will be presented.
\end{abstract}

\section{Keywords}

Neolithic Ceramics, EDXRF, Micro-XRF, Albania

\section{Introduction}

Analysis of pottery from excavations involves two main lines of inquiry. The first, 
termed typological analysis consists chiefly of detailed analysis of the rim forms and decorative features of vessels. The other line of inquiry involves the examination of pottery fabrics - the aim here being to determine the raw materials and processes used in the manufacture of pottery. The results of both fabric analysis and typological analysis can then be combined to establish definitive pottery styles which will help in the interpretation of archaeological excavation.

While the typological study of the pottery is widely used by the archaeologists in Albania, only a few studies related with pottery materials and their production technology are published [1] [2] [3]. The main objective of the present study is the collection of data for the materials (clay composition and pigments) and technology (tempers and firing conditions) used for the manufacture of pottery excavated at the different early Neolithic sites and based on them to find similarities and/or differences that can be useful for better archaeological classifications.

In this context different X-ray techniques EDXRF (Energy Dispersive X-ray Fluorescence), Micro-XRF (Micro X-ray fluorescence), XRD (X-ray diffraction), Optical Microscopy together with various multivariate techniques are being used for the characterization of the raw materials and investigation of the technologies used for the production of ceramic finds from different sites in Albania. EDXRF spectrometry was employed for the determination of the chemical composition of the pottery. The evaluation of the chemical data through simple elemental biplots and their treatment by means of multivariate statistical analysis (CA) led to the potential classification of the samples into distinctive groups and provided feedback for further discussion about their provenance. OM, XRD and $\mu$-XRF were used for the investigation of the internal texture of the ceramic body and identification of the major types of inclusions as well as the materials used for the external decorations.

\section{Archaeological Background}

The geographical position of Albania, at the intersection of land routes that connect Anatolia, the Balkans and the Western Mediterranean on one side and its long Adriatic and Ionian coast on the other side, has determined the cultural features of its Neolithic civilization which combines elements of the Anatolian-Balkan and Adriatic-Mediterranean cultural complexes [4].

Pottery manufacturing during early Neolithic in Albania is classified in two major groups: north culture represented by Kolshi and Blazi sites and south culture represented by Vashtëmi-Podgorie sites (Figure 1).

The classic phase of Early Neolithic in south-eastern Albania is represented by the Vashtemi-Podgori culture, two sites situated in the Korça basin. The excavations of 1974 in Vashtemi revealed a deposit consisting of a single layer with three horizons, characterized more or less by similar types of pottery, namely red monochrome pottery in the main, pottery with white decoration on a red ground, and, very rarely, pottery with red decoration on white, ochre or light ground. All these features are equally evident in some huge deposits at the village of Podgorie, about eight kilometers northeast of Vashtemi. Strong typological 


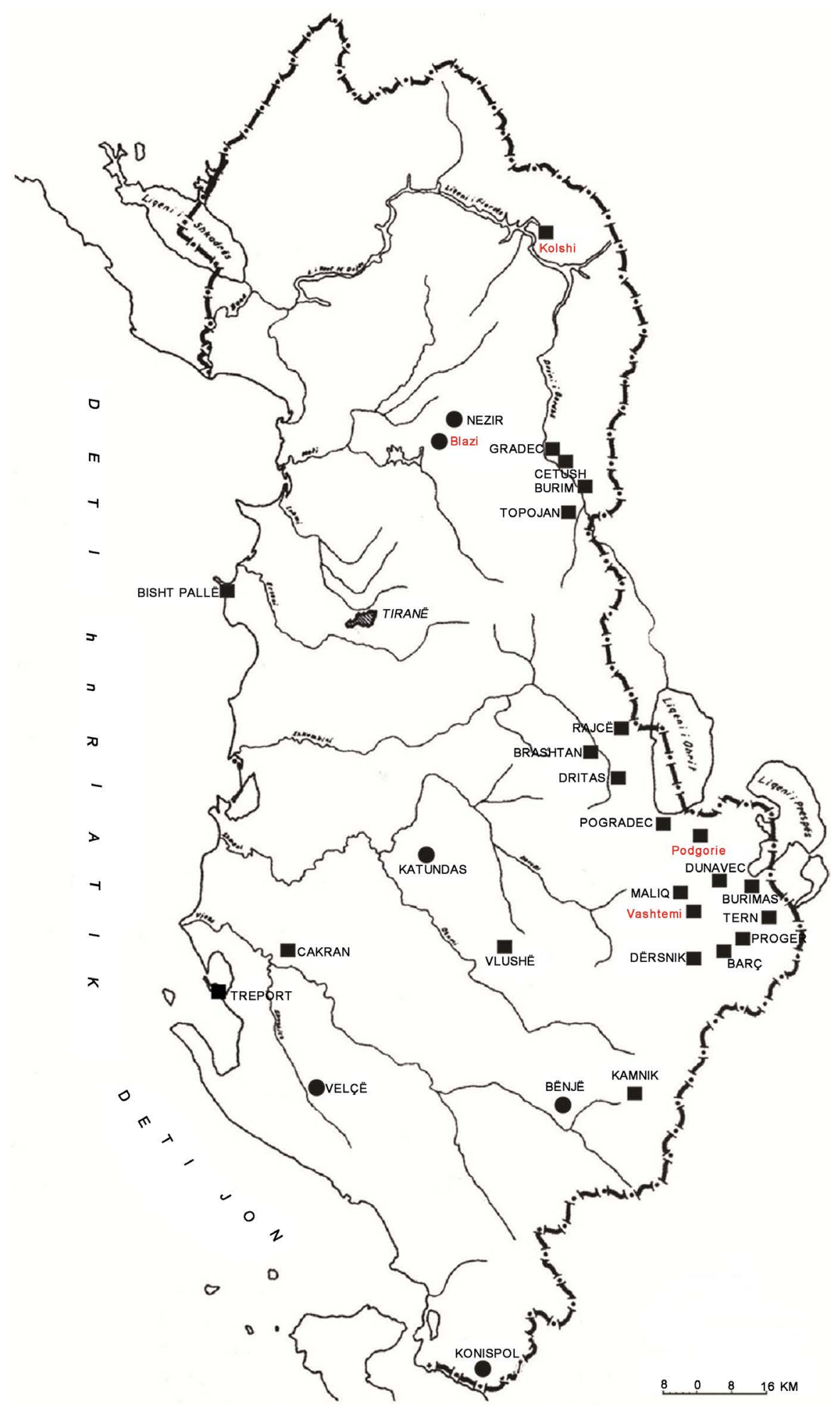

Figure 1. The distribution of Neolithic cultures in Albania.

similarities of the finds from this area with the finds from the Early Neolithic in the area of Thessaly indicate a direct cultural report between them. Pottery with' impressed' decoration or Barbotine pottery was also found in minor quantity mainly in the upper horizons [4] [5]. The last excavations (2006-2013) and core 
dates in Vashtëmi place it within the first wave of Early Neolithic settlements in the Korça basin. This recent study dates Vashtemi between 6470-6370 cal BC and Podgori between 6070-5970 cal BC [6].

The Blazi cave settlement, located in Mati river valley in northeast of Albania, was excavated by F. Prendi and Zh. Andrea from 1978 to 1979. Blazi early Neolithic culture shows special features that tie it with Adriatic group of Early Neolith. Blazi ceramics is characterized by coarse pottery, with grey, black or brown burnished exterior and predominantly Impresso type of decorations [4] [5].

Kolshi culture was excavated in 1974 due to some superficial findings from an expedition in Kukësi area. Kolsh ceramics is mainly with thick walls, with brown or reddish colour and barbotine decorations. The amount of fine ceramics is relatively small, and appears in carefully modeled shapes, with small dimensions and thin walls. The sherds from Kolsh are decorated with geometric motifs of red or dark brown colors on red background. The Kolsh culture shows similarities and connections with the culture of central Balkans [4] [5].

Although these cultures sprang from different origins, they were not isolated in their development but on the contrary entered into close contact with one another. This may be seen in the interchange of cultural elements, those of east Albania appearing in west Albania and vice versa; for example, the Barbotine pottery of Starcevo appearing in Blaz II, or "impress" pottery of Adriatic type at Vashtemi [4] [5].

\section{Samples and Sample Preparation}

We will consider here a small group of pottery shards from the collection of the excavations at four early Neolithic sites in Albania. The sites named Vashtemi and Podgori are situated in south east of Albania, while the sites named Kolsh and Blaz are situated respectively in the northeastern and northwestern part of the country. 20 - 30 shards from each site were selected by the archaeologists and we were allowed to cut small pieces and use them for the analysis. The shards from all the sites belong to pottery with thick and thin walls (Figure 2). Most of the shards show dark red and black color with black layers in the middle and some of them are painted on the surface.

Fresh cross sections of some of the shards were polished on successive grades of grinding paper (silicon carbide) and after cleaning and drying were used for optical microscopy and micro-XRF examinations. Standard thin sections have been prepared from the ceramic shards for the mineralogical and petrographic characterization.

The samples for EDXRF analysis were prepared in the form of thick pressed pellets. The shards were first cleaned from depositions (washed with distilled water) and dried overnight at $1050 \mathrm{C}$. Small pieces (5 - $6 \mathrm{~g}$ ) were cut from the shards and were crushed and grinded in a mixer/mill for $15 \mathrm{~min}$. The fine powder ( $<200$ mesh) was converted to a pellet by pressing at $245 \mathrm{kN}$. The clay samples were treated and prepared in the same way. A portion of $1-2$ grams 


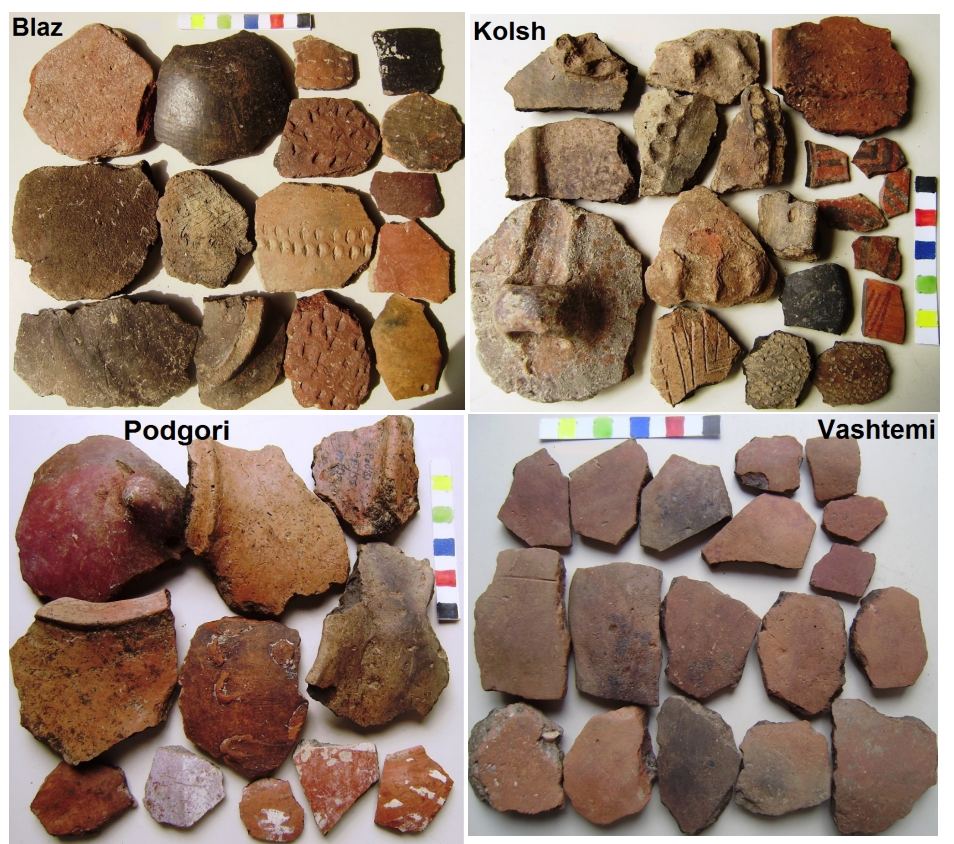

Figure 2. Ceramic shards from the studied sites.

from the same fine powder, placed in the sample holder with a flat surface, was used for XRD analysis in reflection mode.

\section{Analytical Techniques}

The microscopic petrographic investigations were carried out on a Leitz Laborlux 11 Pol S polarizing microscope.

The Micro-XRF spectrometer ARTAX 800 (Bruker) was used for the investigation of the ceramic cross sections and their surface decorations. The main parts of the spectrometer consist of an air cooled X-ray microfocus Rh-anode tube and a polycapillary X-ray lens (X-ray beam with spot size of $75 \mu \mathrm{m}$ ), an electrothermally cooled $10 \mathrm{~mm}^{2}$ silicon drift detector (X-Flash) coupled with a digital signal processor and three stepping motors used for moving the measuring head in X, Y, Z directions. A colour CCD camera and a spot laser beam allow the reproducible positioning of the measuring head, as well as the visualization and documentation of the analyzed area. Helium atmosphere can be used to improve the excitation and detection efficiency of the low atomic number elements $(\mathrm{Na}, \mathrm{Mg}, \mathrm{Al}, \mathrm{Si}$ ). The spectrometer allows the collection of X-ray maps from the ceramic surface with a spatial resolution in the sub-mm range. In each pixel a spectrum was collected and the net characteristic peak areas of the detected elements were calculated. The X-ray maps, showing the variation of the element intensity over the measured area, were constructed using the three-dimensional matrix (X-pixels, Y-pixels, I-elements) and plotted in intensity readouts graphs. During the measurements the spectrometer was operated close to the maximum power $(45 \mathrm{kV}, 500 \mu \mathrm{A})$. The primary radiation was not filtered and the measuring time of $20 \mathrm{~s}$ per pixel allowed statistically significant intensities for most of 
the elements in the spectra. Areas up to $10 \mathrm{~mm}^{2}$ with spatial resolution of 0.1 mm were scanned in 5 - 6 hours.

The elemental composition of the samples was determined by EDXRF spectrometry. Two different EDXRF systems were used for the effective excitation of more than 20 elements in each sample. Elements from $\mathrm{K}$ to $\mathrm{Zr}$ were excited by a Mo secondary target and the $59.6 \mathrm{keV}$ radiation of Am-241 source was used to excite the $\mathrm{K}$ lines of some heavier elements ( $\mathrm{Ba}-\mathrm{Nd})$. The first system that uses the secondary target excitation mode, consists of a Philips $1729 \mathrm{X}$-ray generator equipped with Mo anode X-ray tube (max. $50 \mathrm{kV}{ }^{\star} 40 \mathrm{~mA}$ ); a $30 \mathrm{~mm}^{2}$ Canberra Si(Li) detector, while the second system is based on $30 \mathrm{mCi} \mathrm{Am-241} \mathrm{excitation} \mathrm{source}$ and $80 \mathrm{~mm}^{2}$ PGT HpGe detector. Both systems use a 900 source-sample-detector geometry and similar pulse processing chains consisting of Canberra spectroscopy amplifier (Mod. 2024), ADC (Mod. 8706), S-100 and Accuspec B MCA cards installed on separate PC-s and Gennie 2000 software. Thin Mo and Pb foils were respectively used for filtering the scattered radiation and the low energy lines of the Am source in each of the systems. The operating conditions of each measurement are presented in Table 1.

The intensities of the analytes' line were calculated by the program AXIL [7]. An approximate sample composition, peak shape correction together with the other required parameters were included in the fitting model. The program COREX [8], which uses back scattered peaks and fundamental parameters, was used for the calculation of the concentrations of the elements excited by Mo secondary target. A set of about 40 "calibrators" prepared from pure elements and or compounds were measured in the same conditions and the results were used for the required experimental calibrations (Excitation-detection efficiency vs atomic number, mass absorption coefficient at Compton energy vs the intensity of Compton Peak and average atomic number of sample vs the ratio of the scattered peaks). The concentrations of $\mathrm{Ba}, \mathrm{La}, \mathrm{Ce}$ and $\mathrm{Nd}$, excited by the Am-241 source, were calculated using the Compton scattered peak as internal standard [9]. As the composition of ceramic samples are generally similar to that of soils and sediments, a series of sediment reference materials (GSD1-12, Chinese stream sediment SRM-s [10], IAEA standards SL-1, Soil-5 and Soil-7 [11]) were used for calibration in this case.

In these conditions we could detect more than 20 elements in each ceramic sample. The calculated values of detection limits for the elements excited by the Mo secondary target vary from $150-100 \mathrm{mg} / \mathrm{kg}$ for K and Ca, $40-15 \mathrm{mg} / \mathrm{kg}$ for elements $\mathrm{Ti}$ - Fe and $4-12 \mathrm{mg} / \mathrm{kg}$ for Ni - Zr. The elements excited by Am-241

Table 1. Operating conditions of EDXRF measurements.

\begin{tabular}{ccccc}
\hline Elemental range & Source & Filter & $\mathrm{kV} / \mathrm{mA}$ & Time (s) \\
\hline $\mathrm{K}-\mathrm{Zr}$ & Mo sec. target & $\mathrm{Mo}$ & $35 / 20$ & 1500 \\
$\mathrm{Sn}-\mathrm{Nd}$ & $\mathrm{Am}-241$ & $\mathrm{~Pb}$ & - & 2000 \\
\hline
\end{tabular}


source show values of detection limits in the range $8-10 \mathrm{mg} / \mathrm{kg}$. The precision of the procedure was evaluated by repeated measurements of the Standard Reference Material GSS-1 (Chinese soil SRM) [10], which was frequently measured together with the samples. From the data summarized in Table 2 it can be seen that the relative standard deviations for major elements are better than $5 \%$, while for minor elements it is generally within 15\%, except for some elements that suffer line interferences, blank subtraction or have concentrations close to detection limit. The good agreement between the certified and the calculated concentrations for this standard is an indication of the good accuracy of the analytical procedure. Additional information about the EDXRF system and the analytical parameters of the procedure can be found elsewhere [12] [13].

PANALYTICAL XPERT-PRO MPD PW diffractrometer was used for X-Ray diffraction analysis of some of the pottery samples. It is an X-ray computer controlled diffractometer system, having a fixed tube $\mathrm{Cu}$ target, secondary graphite

Table 2. Reproducibility of the determinations.

\begin{tabular}{|c|c|c|c|c|}
\hline \multirow{2}{*}{ Element } & \multirow{2}{*}{$\begin{array}{c}\text { GSS-1 } \\
\text { Certified }\end{array}$} & \multicolumn{3}{|c|}{ Calculated } \\
\hline & & Average & St Dev & Rel St Dev (\%) \\
\hline $\mathrm{K}(\%)$ & 2.150 & 2.156 & 0.087 & 4.2 \\
\hline $\mathrm{Ca}(\%)$ & 1.230 & 1.181 & 0.045 & 4.0 \\
\hline $\mathrm{Ti}(\%)$ & 0.483 & 0.462 & 0.022 & 5.0 \\
\hline $\mathrm{Fe}(\%)$ & 3.630 & 3.675 & 0.053 & 1.5 \\
\hline $\mathrm{V}$ & 86.0 & 102.7 & 25.7 & 26.3 \\
\hline $\mathrm{Cr}$ & 62.0 & 66.7 & 11.9 & 18.7 \\
\hline $\mathrm{Mn}$ & 1760.0 & 1750.7 & 48.2 & 2.9 \\
\hline $\mathrm{Ni}$ & 20.4 & 23.4 & 4.4 & 19.7 \\
\hline $\mathrm{Cu}$ & 20.9 & 24.5 & 5.5 & 22.7 \\
\hline $\mathrm{Zn}$ & 680.1 & 672.8 & 15.8 & 2.5 \\
\hline $\mathrm{Ga}$ & 19.3 & 17.8 & 1.9 & 11.4 \\
\hline As & 33.5 & 32.7 & 5.5 & 17.7 \\
\hline $\mathrm{Rb}$ & 140.0 & 143.7 & 1.8 & 1.3 \\
\hline $\mathrm{Sr}$ & 155.0 & 162.7 & 2.3 & 1.5 \\
\hline $\mathrm{Y}$ & 24.9 & 25.8 & 1.3 & 5.3 \\
\hline $\mathrm{Zr}$ & 245.0 & 244.4 & 12.1 & 5.2 \\
\hline $\mathrm{Pb}$ & 98.0 & 108.9 & 5.3 & 5.1 \\
\hline Th & 11.6 & 11.2 & 1.2 & 11.7 \\
\hline $\mathrm{Ba}$ & 590.0 & 585.5 & 7.4 & 1.3 \\
\hline $\mathrm{La}$ & 34.0 & 30.4 & 4.5 & 14.5 \\
\hline $\mathrm{Ce}$ & 70.0 & 67.1 & 2.1 & 3.3 \\
\hline $\mathrm{Nd}$ & 28.0 & 27.9 & 2.5 & 9.5 \\
\hline
\end{tabular}


monochromator, flat plate horizontal sample holder and X-Celerator for the faster acquisition of data. The diffractogram patterns were obtained by continuous scanning from $7.5 \mathrm{o}-90 \mathrm{o}$ as $2 \theta$ angle. Angle step size is $0.013 \mathrm{o}$ and step time is 30 seconds. It was operated at $40 \mathrm{kV}$ and $40 \mathrm{~mA}$ with a source of CuKa radiation of wavelength $\lambda=1.5405 \AA$.

The Windows based software package IDAS [14], which includes Hierarchical Cluster Analysis (HCA) and other multivariate methods, was used for data processing. HCA included in IDAS uses Euclidian distance as dissimilarity measure and minimum variance (Ward's method) as clustering strategy. Centered log ratio transformation was applied to the concentration data [15].

\section{Results and Discussions}

\subsection{Mineralogical Composition}

A small number of samples (3 - 4) from each site were investigated for their mineralogical composition using thin section petrography and X-ray diffraction. From each group we selected samples with different chemical composition.

The colour of the ceramic body varies from reddish-yellow to brown or reddish-brown. In cross section, the ceramic wall presents in general a bilayered texture, marked by an outer layer with lighter colour and an inner layer with darker colour (Figure 3). According to Rye [16], this type of structure can be due to firing in reducing conditions with an oxidizing cooling stage, or to firing organic matter-rich clays in oxidizing conditions. In either of these cases, it is difficult to judge the firing condition by naked eye observation of the paste colors.

The thin section petrographic examinations show that generally the fabric of the ceramic body is made of semifine clays with amorphous-microcrystalline structure and contains several voids with spherical and elliptical shape as well as different natural non-plastic inclusions, which belong either to the raw materials or were added as temper (Figure 4). The grains of the inclusions are generally angular to sub-angular and range from $1-3 \mathrm{~mm}$ in size. They constitute $10 \%$ $15 \%$ of the volume in the shards from Kolsh and Blazi and about $5 \%$ in the sherds from Vashtemi and Podgorie.

In the shards from Kolsh and Blaz the non-plastic inclusions are mainly composed of quartz, plagioclase, mica (muscovite), clinopyroxene, calcite and opaque

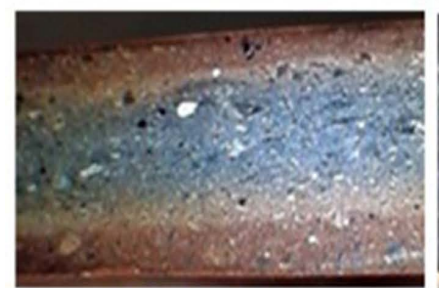

Kolshi

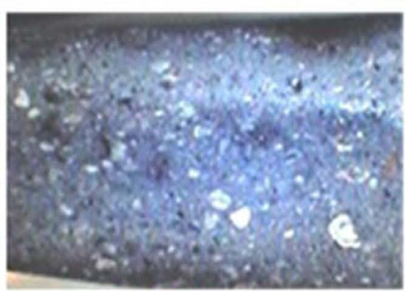

BIazi

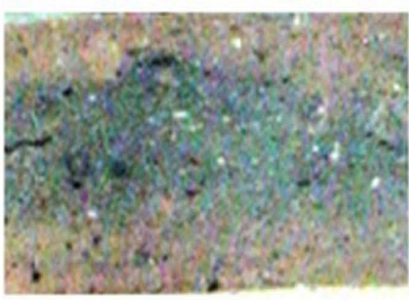

Vashtemi

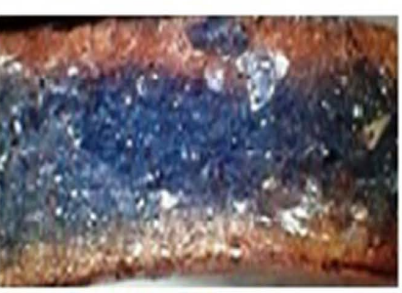

Podgori

Figure 3. Cross sections of some shards. 


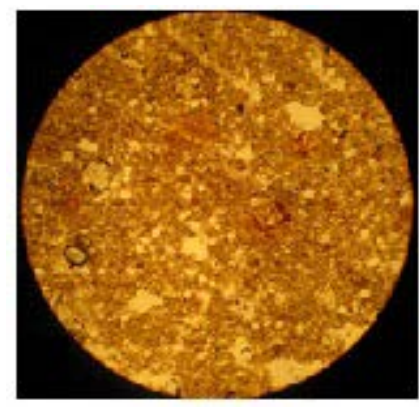

(a)

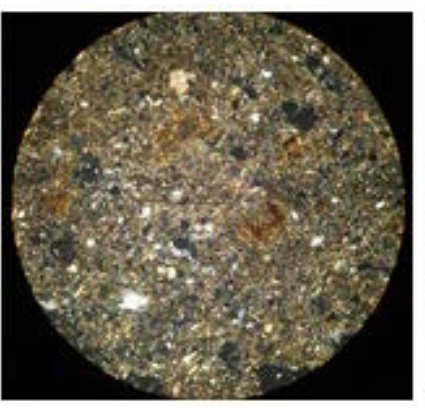

(b)

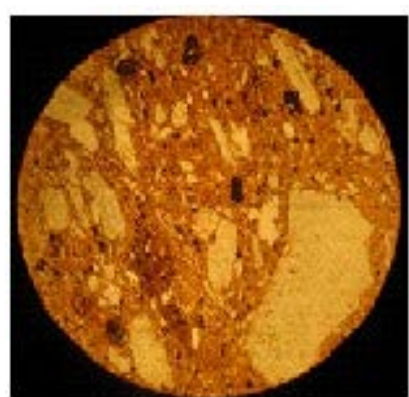

(c)

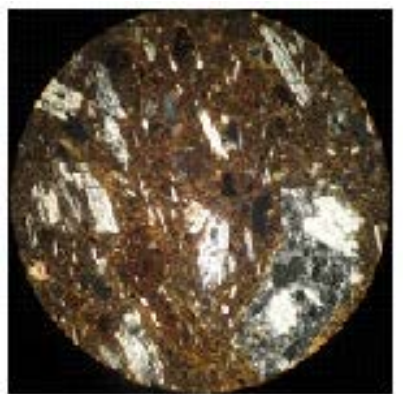

(d)

Figure 4. Thin section micrograph of Pod Nr. 813 (a), (b), Blaz Nr. 44 (c), (d). Images taken in plane polarized light and in cross-polarized light (PPL, XPL, $\times 10)$.

minerals represented by hematite, while those form Vashtemi and Podgorie are mainly composed of quartz, plagioclase, mica (muscovite). Small potsherds and vegetal remnants (transformed into carbon) were also identified in some of the shards from each group.

X-ray maps obtained by micro-XRF spectrometer on a small area (10 - 15 $\mathrm{mm}^{2}$ ) of the cross section of some shards allow an approximate identification of some of the mineral inclusions in the respective clays. Intensity distribution maps (Figure 5) show the presence of $\mathrm{Si}, \mathrm{K}, \mathrm{Ca}$ and Fe rich particles, which can indicate the presence of the minerals rich in those elements, like silicates, calcite, K-feldspars, hematite, etc.

A limited number of samples from Vashtemi, Podgori, Blaz and Kolsh and the raw clays collected in the area of Vashtemi and Podgori were investigated with $\mathrm{X}$-ray diffraction for the identification of main mineral phases (Figure 6).

The data collected are summarized in Table 3. These data show that quartz and albite are the main mineral phases observed in the shards for Vashtemi and Podgori, while in the shards from Blaz and Kolsh in addition to them calcite, diopsite and hematite are also identified. This is in accordance with thin section petrographic results where clinopiroxen, calcite and hematite were observed among the non plastic inclusions of the shards from Blaz and Kolsh. This should be related with the different geological formations of the areas where the sites are located.

\subsection{Elemental Composition}

As was previously stated we have analyzed by EDXRF 96 ceramic shards from the Early Neolithic sites of Vashtemi, Podgori, Kolsh and Blaz. In each sample we have determined around 20 elements that include both major and minor elements.

The samples from each site were considered as a separate group and the range of concentrations for each element in the samples from each site are presented in Table 4.

Using the chemical data obtained by EDXRF for the body of all studied samples, bivariate graphs representing concentrations of $\mathrm{Fe}_{2} \mathrm{O}_{3}-\mathrm{CaO}$ and $\mathrm{Zr}-\mathrm{Sr}$ are plotted in Figure 7(a) and Figure 7(b). 

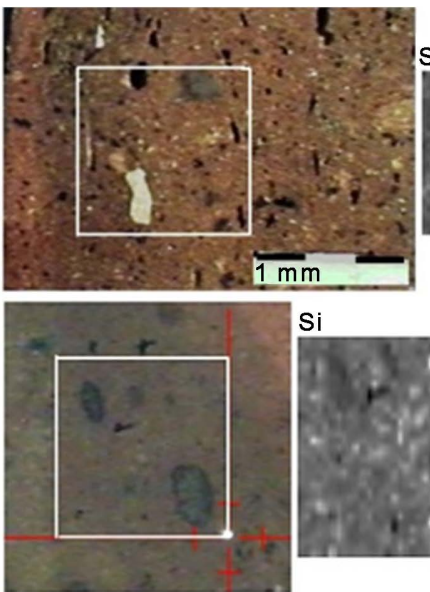
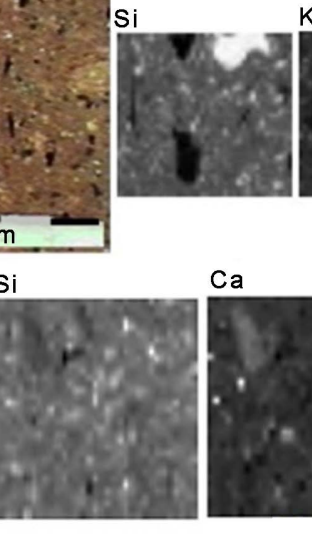
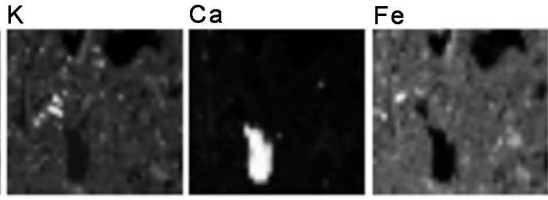

Vashtemi (Nr:3)
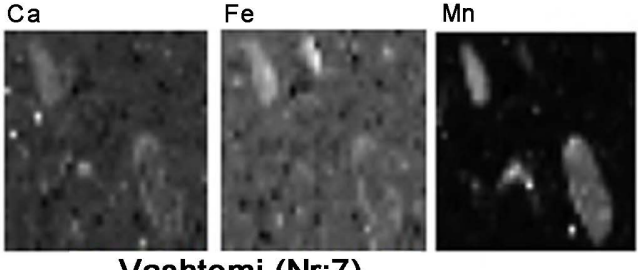

Vashtemi (Nr:7)

Figure 5. X-ray intensity distribution maps from the cross sections of some shards.
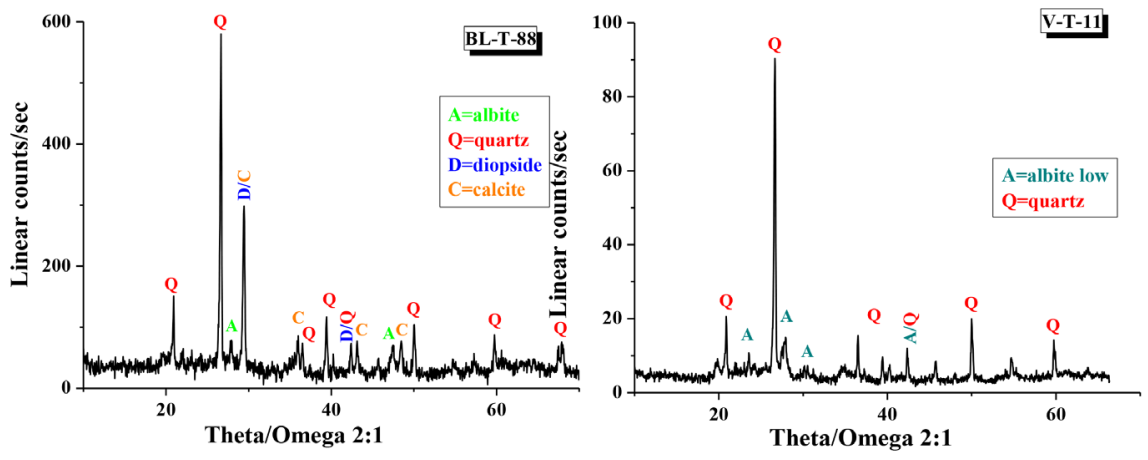

Figure 6. XRD spectra of two representative samples from Blaz and Vashtemi.

Table 3. The main mineral phases identified by XRD.

\begin{tabular}{|c|c|c|c|c|c|}
\hline & Quartz & Calcite & Hematite & Albite & Diopsite \\
\hline P-CLAY & + & + & & + & \\
\hline Podgori T 1110 & + & & & + & \\
\hline Podgori T 700 & + & & & + & \\
\hline Podgori H 1230 & + & & & + & \\
\hline Podgori H 1343 & + & & & + & \\
\hline V-CLAY & + & & & + & \\
\hline Vashtemi T 2 & + & & & + & \\
\hline Vashtemi T 11 & + & & & + & \\
\hline Blazi H 57 & + & & & & + \\
\hline Blazi H 189 & + & & & & + \\
\hline Blazi T 88 & + & + & & + & + \\
\hline Blazi T 227 & + & & + & + & + \\
\hline Kolsh T 427 & + & + & & + & \\
\hline Kolsh T 1179 & + & & + & + & + \\
\hline Kolsh H 887 & + & + & & + & \\
\hline
\end{tabular}


Table 4. The concentration range of the elements analyzed in the shards from each site. Concentrations in $(\mathrm{mg} / \mathrm{kg})$ unless otherwise indicated.

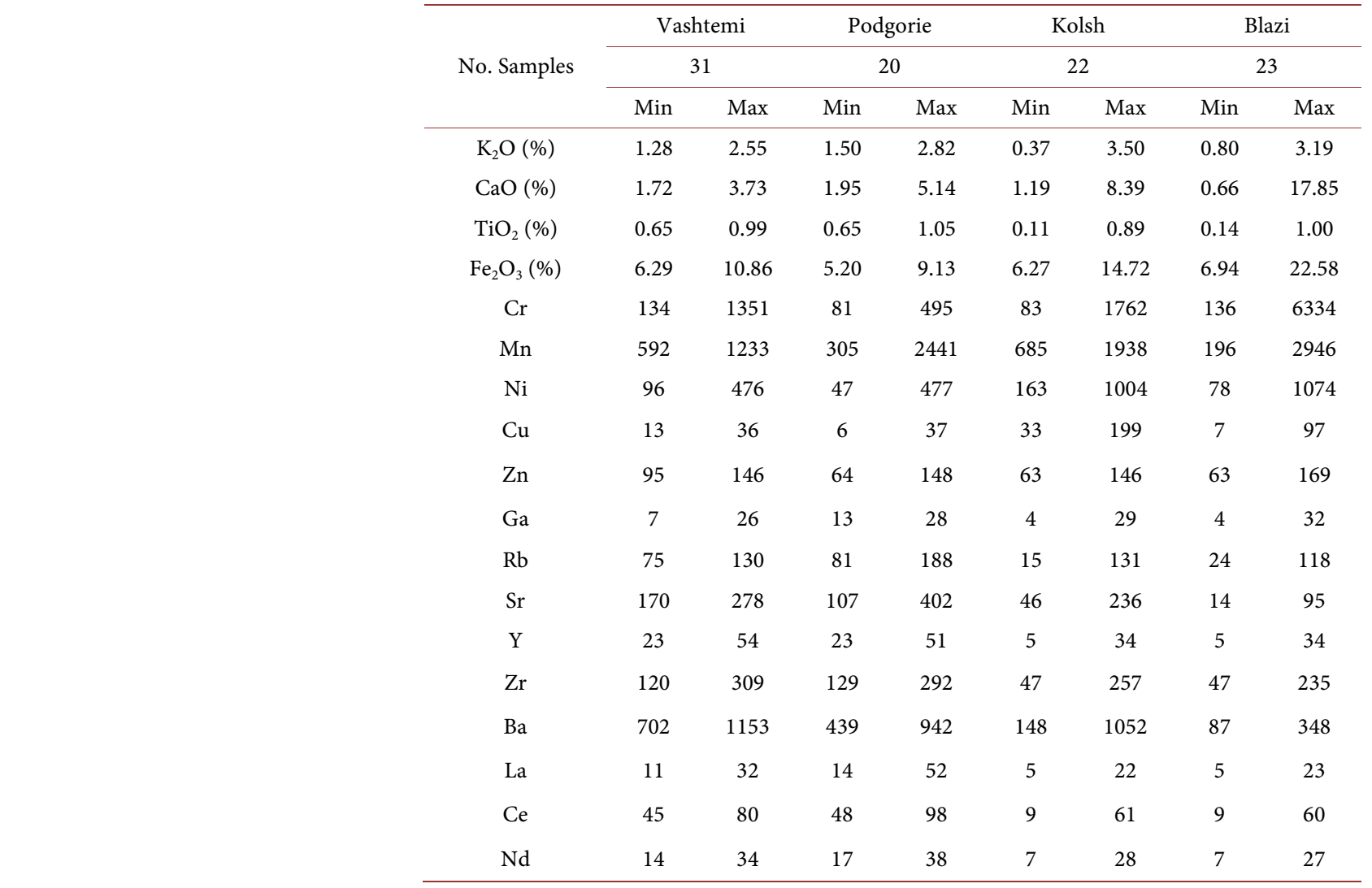

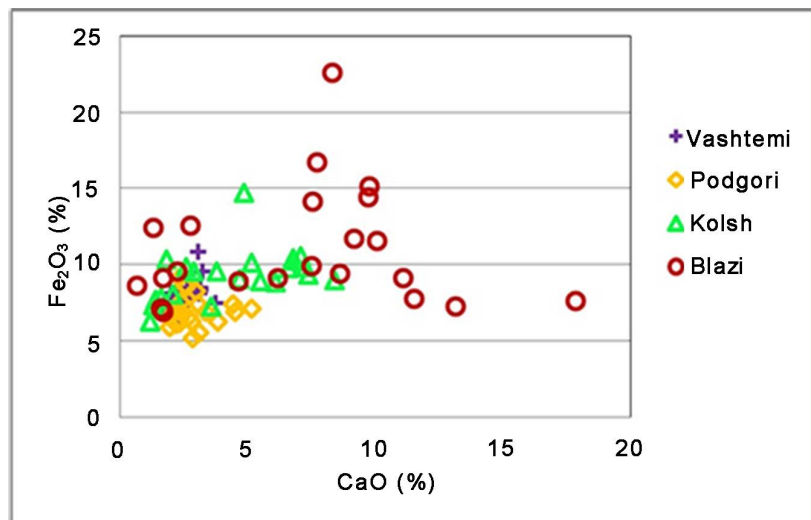

(a)

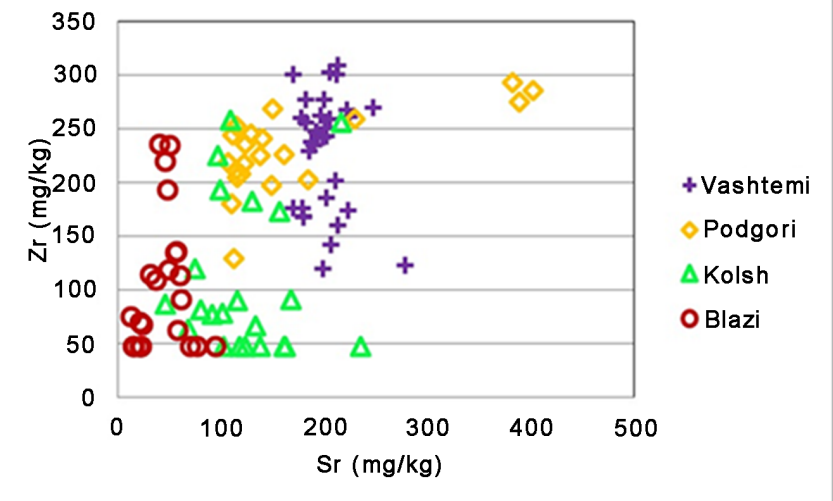

(b)

Figure 7. Bivariate plots of $\mathrm{Fe}-\mathrm{Ca}$ and $\mathrm{Zr}-\mathrm{Sr}$ of all the samples.

From Figure 7(a), some initial conclusions can be derived regarding the raw materials employed for the production of the various pots, since they are directly connected to the chemical composition of the clay. The first indication obtained by the results is that almost all samples from Vashtemi and Podgorie exhibit low concentrations of $\mathrm{Ca}$ indicating the use of low calcareous raw materials (Ca-poor clays) for the manufacture of these wares. Generally, clays with $\mathrm{CaO}$ concentration less than $5 \%(\mathrm{Ca}<3.6 \%)$ are considered non-calcareous [17]. The situation 
looks different for the shards from Kolsh and Blaz where respectively $45 \%$ and $60 \%$ of the shards are made of calcareous clays $(\mathrm{CaO}>5 \%)$.

Concerning the $\mathrm{Fe}_{2} \mathrm{O}_{3}$ concentration in the body paste of the samples, it is obvious from Figure 7(a) and Table 4 that in the samples from Blaz it varies in a much wider range compared with the other groups. Its concentration is quite high in one sample from Kolsh and 5 samples from Blaz.

Bivariate plots of different major and minor elements indicate that most of the shards from Vashtemi and Podgori constitute rather compact groups although there are a few shards which can be considered as outliers from each group (Figure 7). It is worth noticing that in most of the cases the between group differences are not so large and the groups overlap but for some elements there exist observable differences of the concentration ranges of samples from different sites which can constitute evidence that different clay sources may have been used for these wares (Figure 7(b)). The situation appears different for the shards from Kolsh and especially Blaz where the concentrations of the elements vary in a wider range suggesting a quite frequent change of raw materials or different provenance of the pots.

A multidimensional data set consisting of 96 samples (rows) and 18 elements (columns) was created, demanding a multivariate statistical interpretation in order to extract the maximum useful archaeometric information. Hierarchical Cluster Analysis (HCA), specified earlier, was applied to the data matrix. It is worth mentioning that analytical variability, as presented in Table 2, doesn't influence the HCA results. In test runs of the HCA we included in the data set the results of one clay sample that was measured several times together with the samples and we found out that these artificial samples were always clustered together in the same cluster without affecting the general cluster structure.

HCA results with five clusters offers an acceptable resolution of the shards from different sites. The dendrogram in Figure 8 shows that the maximum dissimilarity is observed between the majority of the shards grouped in clusters C3, C2 and $\mathrm{C} 5$ and the samples grouped in clusters $\mathrm{C} 1$ and $\mathrm{C} 4$.

The majority of the shards from Vashtemi, Podgorie and Kolsh are grouped in separate clusters with specific compositional profiles. In cluster 3 we have a group consisting mainly of the shards from Vashtemi (87\% of them), $75 \%$ of the shards from Podgori are grouped in cluster 2, while in cluster 1 are grouped $73 \%$ of those from Kolsh. This is a strong indication of the local production activities at those sites. As it was previously mentioned, the shards from Blaz, showing a large variability of the elemental composition, are distributed between several clusters (C1, C2, C4 and C5). The clusters C4 and C5, with quite different compositional profiles, include mostly shards from Blaz (about $45 \%$ of them). The other shards from Blaz are distributed between the cluster $\mathrm{C} 1$ of Kolsh (8 shards) and the cluster C2 of Podgori ( 4 shards). Although there is clearly need for more research related with the shards from Blaz, based on these results both hypothesis of local production and import of pottery from other sides can be supported. 


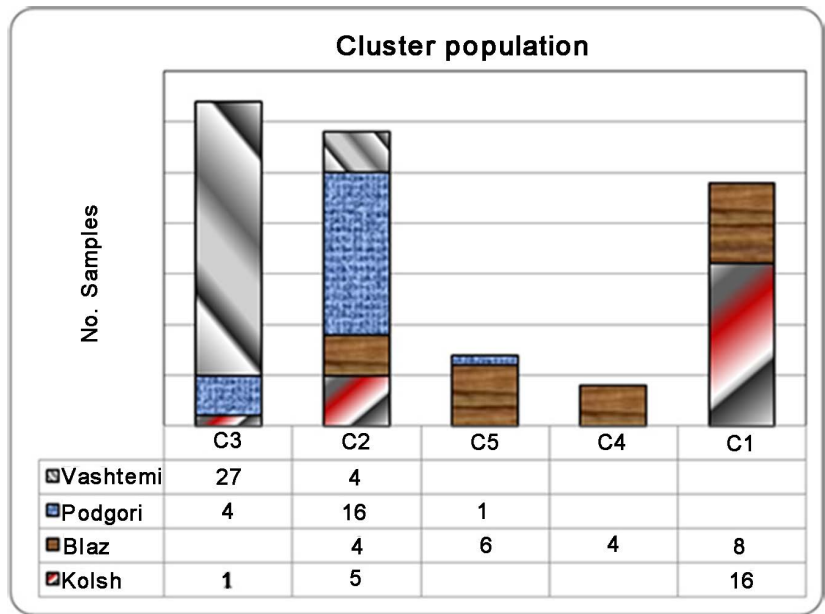

(a)

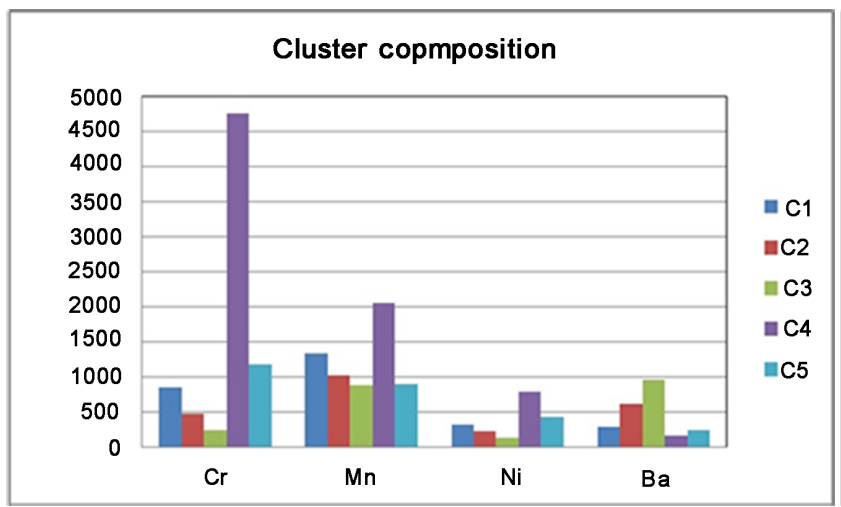

(c)

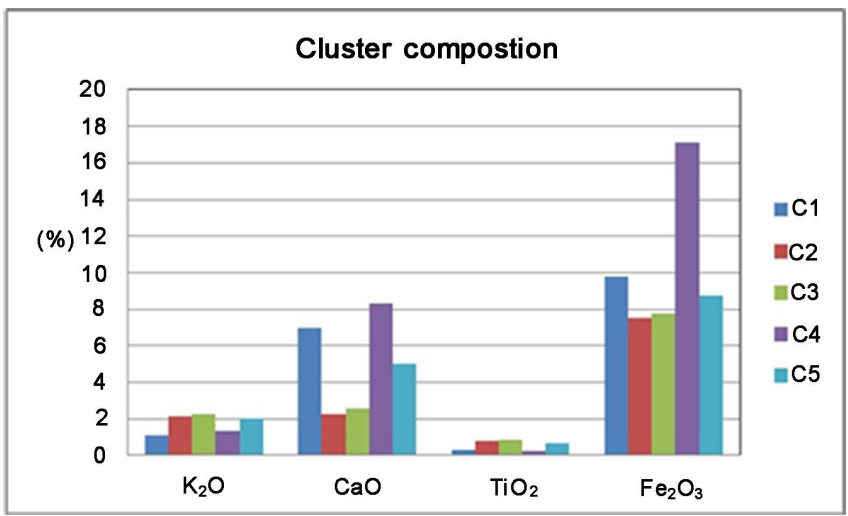

(b)

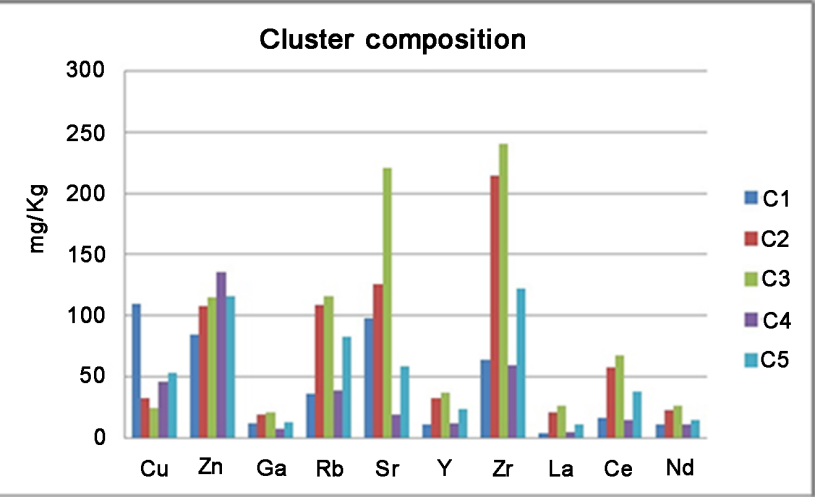

(d)

Figure 8. Results of the hierarchical cluster analysis; dendrogarm, cluster population and cluster composition.

The presence of clusters $\mathrm{C} 4$ and $\mathrm{C} 5$ could indicate local production with different raw materials (clays and/or temper), while the similarities of a big number of shards with those from the sites of Kolsh and Podgorie could indicate commercial connections with those sites.

In conclusion we can state that separate clay deposits, close to each site, have been used for local ceramic production in the sites of Vashtemi, Podgorie and Kolsh. The variability of the chemical composition of the shards from Blaz supports both the local production and the import from other sites. We also observe that in each site the shards with thin and thick walls are clustered together, which means that they are manufactured using the same type of raw materials. The inclusion in the cluster C2 (group of Podgori) and C3 (group of Vashtemi) of a few shards from other sites could be an indication of the exchanges that could have been exiting between the sites. However, more research is needed to fully support this hypothesis.

\subsection{Decorations}

Some of the investigated shards, especially those with thin walls from Podgori and Kolsh, have decorations with geometric motifs on the external surface. The 
sherds from Podgori are mostly painted with white color on red background but one of the sherds is painted with bright red color, while the sherds from Kolsh are decorated with red or dark brown colors on red background. Generally the examined shards from Blaz and Vashtemi have not visible coloured decorations, although we have identified the remains of white colour on a shard from Blaz and those of brown colour on a shard from Vashtemi.

Initially the identification of the pigments used for the decorations were performed by comparing the micro-XRF spectra measured at the ceramic body with those from the colored areas, but later we thought that X-ray mapping of small areas from the decorated part of the ceramic could give better results. In this way we can clearly observe the variations of the intensity of different elements and connect the pigment with the respective "key elements".

Some typical examples of the examined decorations are presented in Figure 9. In Figure 9(a) and Figure 9(b) are presented the results from the dark brown decorations of a shard from Kolsh and the remains of such a decoration of a shard from Vashtemi. The increased intensities of Mn and Fe in these decorations indicate the use of manganese rich pigments (some kind of brown earth). From Figure 9(c) it can clearly be observed that the white part of the decoration is rich in $\mathrm{Ca}$ while the red part is rich in $\mathrm{Fe}$, which indicates the use of calcium white (probably calcite) and iron rich material (some kind of red ochre) for the white and red colours of the shards from Podgori. The increased Fe intensity of the red decorated area of the shard compared to the ceramic body indicates that the red colour is due to the application of a pigment and not any kind of red slip. In most of the shards we have found black spots or small areas with black colour which are rich in $\mathrm{Ca}$ and $\mathrm{P}$. According to literature data they should be contaminations related with the environmental conditions of burial [18] [19].

Similar types of pigments were identified in studies of Neolithic ceramics from other areas in Balkans and Europe. Calcite, iron oxides and iron and manganese compounds (magnetite and jacobsite) were identified in the respective white, red and black pigments used to decorate Cucuteni Neolithic ceramics [20] as well as the Neolithic ceramics from North Greece [21]. Red ochre and soot were identified in the red and black decorations of the Neolithic ceramics from Slavonia, Croatia [22], while iron minerals haematite and maghemite were identified in the red decorations of the Neolithic ceramics from southern Spain, the later being an indicator of the firing conditions [23].

\section{Conclusions}

The investigation of ceramic finds from the Neolithic sites of South East Albania with different analytical techniques reveals interesting information regarding the materials and the technology used for their manufacture.

The results show that medium coarse, non-calcareous clays were used for the ceramic manufacture in the Early Neolithic sites in south-east Albania, while the situation looks different for the shards from Kolsh and Blaz where respectively $45 \%$ and $60 \%$ of the shards are made of calcareous clays $(\mathrm{CaO}>5 \%)$. Similar 


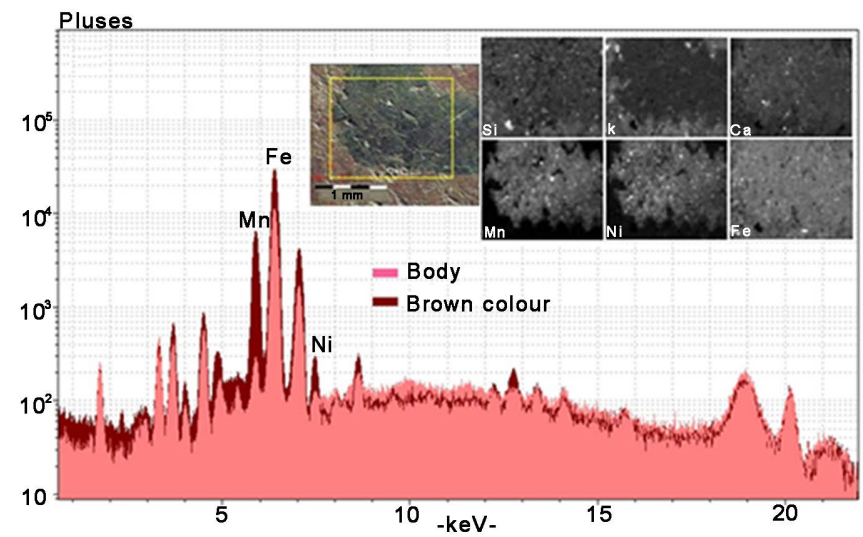

(a)

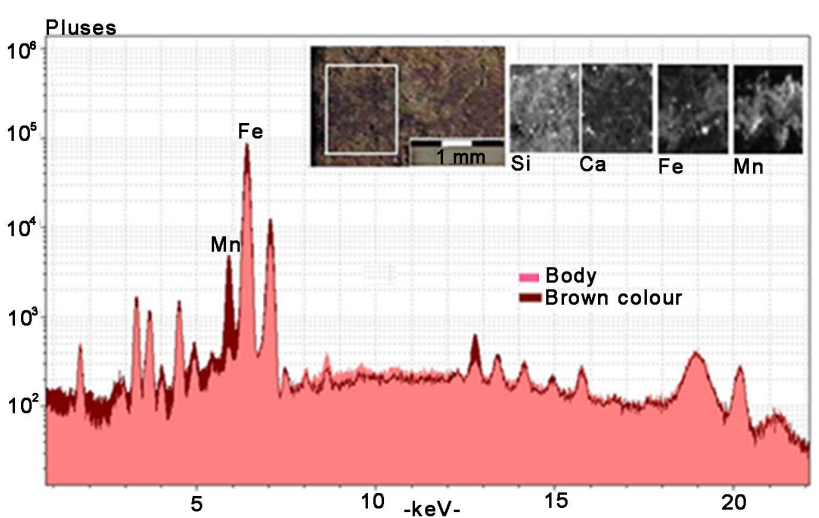

(b)

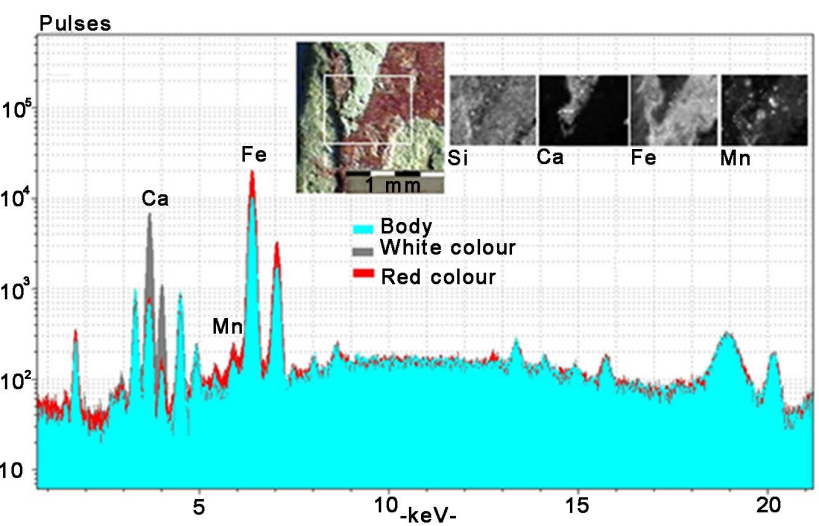

(c)

Figure 9. Comparison of X-ray spectra from the ceramic body and decorated areas and respective X-ray intensity distribution maps from the decorated surfaces of some shards from Kolsh (a), Vashtemi (b), Podgori (c).

differences, probably related with the geological formations of the respective areas, were observed in the mineralogical composition of the shards.

Separate clay deposits close to each site should have been used for ceramic production in Vashtemi, Podgori and Kolsh, while the variability of the chemical composition of the shards from Blaz supports both the local production and the import from other sites.

The examination of decorated sherds mostly from the sites of Kolsh and Podgori revealed that Ca-rich minerals (probably calcite), Fe-rich minerals (red ochre) and Mn-rich minerals (brown earth) were used respectively for the white, red and brown colours. It should be mentioned that similar types of pigments were found by other researchers on the Neolithic ceramics from different sites in Balkan and Europe.

\section{References}

[1] Maniatis, Y., Dilo, T., Civici, N., Pavlidou, E., Paraskevopoulos, K., Polychroniadis, E.K., Stamati, F., Hasa, R. and Gjipali, I. (2002) Technological Investigation of Illyrian Terracotta Aphrodite Figurines and Ceramic Vases from Belesh, Albania. Proceeding of International Seminar Albania-Greece Bilateral Cooperation 2000-2002, MASH, Tirana, 21 November 2002, 107-115. 
[2] Civici, N. (2007) Analysis of Illyrian Terracotta Figurines of Aphrodite and Other Ceramic Objects Using EDXRF Spectrometry. X-Ray Spectrometry, 36, 92-98. https://doi.org/10.1002/xrs.945

[3] Ruzi, E (2013) Investigating Compositional Variability among Early Neolithic Ceramics from Korça Region, Albania. Chronika, Institute for European and Mediterranean Archaeology, 3, 1-15.

[4] Prendi, F. and Bunguri, A. (2013) The Prehistory of Albania. Institute of Archaeology, Tirana, Albania

[5] Boardman, J., Edwards, I.E.S., Hammond, N.G.L. and Sollberger, E. (2008) The Prehistory of the Balkans, and the Middle East and the Aegean World, Tenth to Eighth Centuries B.C. In: Boardman, J., Edwards, I.E.S., Hammond, N.G.L. and Sollberger, E., Eds., The Cambridge Ancient History, Vol. III, Part I, 2nd Edition, Cambridge University Press, Cambridge, 187-207.

[6] Allen, S.E. and Gjipali, I. (2013) New Light on the Early Neolithic in Albania: The Southern Albania Neolithic Archaeological Project (SANAP) 2006-2013. Proceedings of the International Congress of Albanian Archaeological Studies, 65th Anniversary of Albanian Archaeology, Tirana, 21-22 November 2013, 107-120.

[7] Van Espen, P., Nullens, H. and Adams, F. (1977) A Computer Analysis of X-Ray Fluorescence Spectra. Nuclear Instruments and Methods, 142, 243-250. https://doi.org/10.1016/0029-554X(77)90834-5

[8] Orlic, I., Makjanic, J., Ross, J. and Valkovic, D. (1988) A General Way of Solving Matrix Effect Problems in Elemental Analysis by EDXRFS. X-Ray Spectrom, 17, 139-143. https://doi.org/10.1002/xrs.1300170405

[9] Anderman, G. and Kemp, J.W. (1958) Scattered X-Ray as Internal Standarts in X-Ray Emission Spectroscopy. Analytical Chemistry, 30, 1306. https://doi.org/10.1021/ac60140a001

[10] Potts, P.J., Tindle, A.G. and Webb, P.C. (1992) Geochemical Reference Materials Compositions. Whittles Publishing, London.

[11] IAEA AQCS (2002-2003) Reference Materials Catalogue.

[12] Civici, N. and Van Grieken, R. (1997) Energy Dispersive X-Ray Fluorescence Analysis in Geochemical Mapping. X-Ray Spectrometry, 26, 147-152. https://doi.org/10.1002/(SICI)1097-4539(199707)26:4<147::AID-XRS193>3.0.CO;2-X

[13] Ndreçka, E., Vataj, E., Dilo, T., Gjipali, I. and Civici, N. (2014) Application of EDXRF Spectrometry for the Analysis of Ancient Ceramics. 2nd International Conference on Radiation and Dosimetry in Various Fields of Research, Nis, Serbia, 24-26 May 2014.

[14] Bondarenko, I., Treiger, B., Van Grieken, R. and Van Espen, P. (1996) Spectrochim. Electrochimica Acta, 51B, 441.

[15] Aitchison, J. (1986) The Statistical Analysis of Compositional Data. Chapman and Hall, London, 416 p. https://doi.org/10.1007/978-94-009-4109-0

[16] Rye, O.S. (1981) Pottery Technology: Principles and Reconstruction. Taraxacum, Washington.

[17] Tite, M.S. (2008) Ceramic Production, Provenance and Use-A Review. Archaeometry, 50, 216-231.

[18] Fabbri, B. and Gualtieri, S. (2008) Alterazione postdeposizionale di ceramiche neolitiche con formazione di macropori e arricchimento di fosforo. [Postdepositional Alteration of Neolithic Ceramics with Macrophor Formation and Phosphorous Enrichment.] Rendiconti online Società Geologica Italiana, 2, 361-362. 
[19] Maritan, L. and Mazzoli, C. (2004) Phosphate in Archaeological Finds: Implications for Environmental Conditions of Burial. Archaeometry, 46, 673-683. https://doi.org/10.1111/j.1475-4754.2004.00182.x

[20] Bugoi, R., Constantinescu, B., Pantos, E. and Popovici, D. (2008) Investigation of Neolithic Ceramic Pigments using Synchrotron Radiation X-Ray Diffraction. Powder Diffraction, 23, 195-199. https://doi.org/10.1154/1.2958068

[21] Papadopouloua, D., Sakalisa, A., Merousisc, N. and Tsirliganis, N.C. (2007) Study of Decorated Archeological Ceramics by Micro X-Ray Fluorescence Spectroscopy. Nuclear Instruments and Methods in Physics Research A, 580, 743-746.

[22] Lukačevića, I. and Rajković, D. (2015) Non-Invasive Analyses of Ancient Ceramics Colorants. Croatica Chemica Acta, 88, 53-58. https://doi.org/10.5562/cca2516

[23] Capela, J., Huertas, F., Pozzuoli, A. and Linares, J. (2006) Red Ochre Decorations in Spanish Neolithic Ceramics: A Mineralogical and Technological Study. Journal of Archaeological Science, 33, 1157-1166.

\section{Submit or recommend next manuscript to SCIRP and we will provide best} service for you:

Accepting pre-submission inquiries through Email, Facebook, LinkedIn, Twitter, etc. A wide selection of journals (inclusive of 9 subjects, more than 200 journals)

Providing 24-hour high-quality service

User-friendly online submission system

Fair and swift peer-review system

Efficient typesetting and proofreading procedure

Display of the result of downloads and visits, as well as the number of cited articles

Maximum dissemination of your research work

Submit your manuscript at: http://papersubmission.scirp.org/

Or contact msce@scirp.org 